\title{
Produção de edificações sustentáveis: desafios e alternativas
}

\author{
Production of sustainable buildings: challenges and \\ alternatives
}

\section{Mônica Santos Salgado \\ Alain Chatelet \\ Pierre Fernandez}

\section{Resumo}

A discussão do projeto e execução de edificações sustentáveis vem sendo abordada por diferentes autores, em geral com foco no desempenho da edificação e vida útil dos materiais. Entretanto, para atender aos requisitos de desempenho ambiental das edificações, existe também a necessidade de se introduzir mudanças na organização e gestão do processo projetual. Este artigo apresenta os resultados de uma pesquisa que investigou como a incorporação dos requisitos da sustentabilidade ambiental podem influenciar as práticas de projeto de arquitetura e engenharia.

Reconhecendo a influência francesa na produção de edificações sustentáveis no

Mônica Santos Salgado Programa de Pós-Graduação em Arquitetura, Faculdade de Arquitetura e Urbanismo Universidade Federal do Rio de Janeiro Av. Pedro Calmon, 550, Prédio da Reitoria, sala 433, Itha do Fundão

Rio de Janeiro - RJ - Brasil CEP 21941-901

Tel.: 55 (21) 2598-1661 E-mail: monicassalgado@ufrj.br

Alain Chatelet Laboratoire de Recherche en Architecture, Ecole Nationale Supérieure d'Architecture Université de Toulouse 83 rue Aristide Maillol, BP 10629

F - 31106 Toulouse cedex 1

Tél.: 33 (0)5 62115043 E-mail:

alain.chatelet@toulouse.archi.fr

Pierre Fernandez Laboratoire de Recherche en Architecture, Professeur Ecole Nationale Supérieure d'Architecture Université de Toulouse

83 rue Aristide Maillol, BP 10629

F - 31106 Toulouse cedex 1 Tél : 33 (0)5 62115043

pierre.fernandez@toulouse.archi.fr

Recebido em 23/08/11 Aceito em 16/10/12
Brasil - em decorrência da adoção por algumas empresas brasileiras do referencial Aqua (adaptado do $\mathrm{HQE}^{\circledR}$ francês) -, a pesquisa foi realizada junto a empresas que atuam naquele país. Os resultados apontam que a melhoria do processo de projeto depende do estabelecimento de um sistema de gestão que possa auxiliar os profissionais a lidarem com o grande número requisitos relacionados com a edificação sustentável. Também indicam a necessidade de revisão dos esquemas adotados até então, de forma a viabilizar a introdução da interoperabilidade entre os diferentes profissionais de projeto, desde a concepção arquitetônica, que deve se tornar responsabilidade de toda a equipe de projeto.

Palabras claves: Sustentabilidade. Gestão em arquitetura. Projeto integrado.

\section{Abstract}

The discussion around sustainable design and construction has been addressed by different authors, mostly focused on building performance and life cycle of materials. However, the adoption of environmental performance requirements of buildings depends also on the introduction of changes in the organization and management of the building design process. This article presents the results of a research project, which aimed to evaluate how the incorporation of sustainable requirements is affecting the practices adopted in architecture and engineering design. Considering the influence of France on Brazilian architects, particularly due to the adoption of the Aqua method (adapted from HQE ${ }^{\circledR}$ French method) by some Brazilian companies, this investigation was carried out with French companies. The results indicate that the improvement of design process depends on the establishment of a management system that could help professionals to deal with a large number of requirements related to sustainable buildings. They also point out that it is necessary to revise the schemes adopted so far, in order to make it possible the introduction of the interoperability between different design professionals, from the beginning of architecture conceptual phase, which should become responsibility of the whole design team.

Keywords: Sustainability. Architectural management. Integrated design. 


\section{Introdução}

Uma das tarefas fixadas pela Conferência das Nações Unidas sobre o Ambiente Humano, realizada em Estocolmo, em 1972, foi a elaboração de uma nova definição para o conceito de desenvolvimento. A comissão encarregada, liderada pela então primeira ministra da Noruega, Gro Brundtland, produziu, em 1987, o relatório "Nosso Futuro Comum", no qual ficou consolidado um novo conceito, desenvolvimento sustentável, isto é, o desenvolvimento capaz de atender às necessidades das atuais gerações sem comprometer os direitos das gerações futuras (BRUNDTLAND, 1987, p. 16, tradução nossa).

No que tange à construção civil, a Agenda 21 for Sustainable Construction in Developing Countries (INTERNATIONAL..., 2002) apontou, como aspectos a serem considerados no atendimento aos objetivos ambientais, o estabelecimento de metas para o desempenho ambiental das edificações, as mudanças nas práticas de gestão do processo de projeto e construção, e a implantação de uma nova cultura dentro do setor da construção civil, onde todos passariam a valorizar os recursos naturais (água, ar, terra) e as possibilidades de reciclagem e reúso dos materiais.

O Brasil só recentemente deu seus primeiros passos rumo à construção sustentável. Entre as metodologias para o projeto sustentável que chegaram aqui, a francesa $\left(\mathrm{HQE}^{\circledR}\right)$ foi adaptada, resultando na certificação Aqua. Entende-se que o projeto e a construção de edificações sustentáveis exigirão dos profissionais e empresas uma organização diferente, que considere a possibilidade de realizar o projeto de forma integrada. Esse novo método de projeto implicaria mudanças que se estenderiam desde a organização de documentos até o treinamento dos operários no canteiro de obras.

Considerando a influência francesa no Brasil (no que concerne aos métodos para auxílio ao projeto com qualidade ambiental) e a experiência dos profissionais daquele país, com a realização de projetos com qualidade ambiental, realizou-se uma investigação na França, de forma a avaliar de que maneira a incorporação dos requisitos da sustentabilidade ambiental podem influenciar as práticas projetuais adotadas pelas empresas que desenvolvem projeto (arquitetura e engenharia).

Entre os objetivos específicos dessa investigação pode-se destacar o desejo de identificar o impacto que a incorporação das diretrizes relacionadas com a sustentabilidade ambiental pode exercer no processo de projeto e também na gestão e organização das empresas.

\section{Avaliação da qualidade ambiental das edificações}

A década de 90 ficou marcada na construção civil pelas primeiras metodologias voltadas ao auxílio à elaboração de projetos com alta qualidade ambiental. Entre os métodos propostos tem destaque o método inglês BREEAM (UK). Este foi seguido pelo sistema francês, $\mathrm{HQE}^{\circledR}$, e depois pelo LEED $^{\mathrm{TM}}$, norte-americano, em 2000. Uma análise mais aprofundada confirma que a evolução dos sistemas de classificação, em diferentes países, baseia-se nesses métodos (REED et al., 2009).

O Método BREEAM (Building Research Establishment Environmental Assessment) define o padrão para as melhores práticas do projeto para produção da edificação sustentável a partir da atribuição de créditos, em dez categorias, conforme o desempenho alcançado pela proposta. A maioria dos requisitos é negociável, o que significa que é permitido à equipe de projeto escolher a quais requisitos vão atender, de forma a obter a pontuação necessária à certificação (BREEAM..., 2010).

$\mathrm{O}$ método norte-americano LEED $^{\mathrm{TM}}$ tem sido usado como uma diretriz de projeto e método de certificação de terceira parte. Tem como objetivos melhorar o bem-estar dos ocupantes, aumentar o desempenho ambiental e o retorno econômico dos edifícios, e adotar práticas estabelecidas e inovadoras. Para obter a certificação LEED $^{\mathrm{TM}} \mathrm{o}$ projeto-candidato deve satisfazer a todos os prérequisitos e obter um número mínimo de pontos nos requisitos, de forma a atingir os índices propostos. Tendo cumprido os pré-requisitos básicos do programa, os projetos-candidatos são, então, classificados de acordo com o atendimento aos requisitos, dentro do sistema de classificação, existindo quatro níveis possíveis para a certificação (SALGADO; LEMOS, 2005). Ressalte-se que o certificado LEED $^{\mathrm{TM}}$ oferece diferentes escopos de certificação, sendo possível optar pela certificação apenas para a envoltória do edifício (LEED-CS - for Core and Schell), ou para o interior (LEED-CI: for comercial interiors), para citar dois exemplos (em 2012 essa certificação oferecia, no Brasil, oito tipos diferentes) (GREEN..., 2012).

O método francês surgiu a partir da criação, em 1996, da Associação HQE ${ }^{\circledR}$ - Haute Qualité Environmentale (Alta Qualidade Ambiental) -, destinada a promover, dentro da perspectiva de desenvolvimento sustentável, a melhoria da qualidade ambiental das edificações, considerando, 
também, a gestão da qualidade ambiental no desenvolvimento dos projetos das edificações. Conta com a participação de associações públicas ou coletivas (sindicatos), representando todos os atores que participam da produção do edifício empresas gerenciadoras de projetos e obras; fabricantes de produtos de construção; especialistas; representantes regionais, entre outros -, o que garante a pluralidade de pontos de vista dentro do conselho de administração (ASSOCIATION..., 2011).

A Associação $\mathrm{HQE}^{\circledR}$ foi a responsável pela elaboração de um relatório contendo uma série de recomendações, sob forma de alvos ambientais, a serem atendidos pelo arquiteto ou engenheiro, no desenvolvimento dos projetos das edificações. Os alvos ambientais são agrupados em quatro categorias:

(a) ecocontrução;

(b) ecogestão: incluindo a gestão da energia, da água, dos rejeitos da obra, assistência técnica e manutenção;

(c) conforto (térmico, acústico, visual); e

(d) saúde (qualidade do ar e da água).

Essa proposta se concretizou na forma de uma metodologia para auxílio ao projeto com alta qualidade ambiental, em que cada um desses alvos se desdobra em várias exigências e recomendações. As recomendações devem ser analisadas conforme o tipo de projeto, terreno e condições específicas, não existindo a possibilidade de estabelecer uma fórmula única para o atendimento aos requisitos.

Entende-se que os temas-chave para a construção sustentável devem atender ao tripé que define a própria sustentabilidade, incluindo aspectos ambientais, sociais e econômicos. Nesse sentido, o CIRIA (Construction Industry Research and Information Association) realizou uma ampla consulta ao setor de construção no Reino Unido (CONSTRUCTION..., 2001 ${ }^{1}$ apud SILVA, 2007), que resultou nos dez temas-chave para a construção sustentável, apresentados no Quadro 1.

As metodologias de avaliação do projeto com qualidade ambiental, que foram propostas a partir da década de 90 , procuraram, em grau maior ou menor (dependendo da cultura do país), incluir esses aspectos. A facilidade ou não na avaliação das edificações sustentáveis variou conforme as proposições de cada método.

Reed et al. (2009) elaboraram uma comparação entre metodologias de auxílio ao projeto com qualidade ambiental. O Quadro 2 apresenta um extrato dessa comparação, destacando as três metodologias aqui citadas (BREEAM, LEED ${ }^{\mathrm{TM}} \mathrm{e}$ $\mathrm{HQE}^{\circledR}$ ).

Entre os resultados da pesquisa realizada por Reed et al. (2009) destacam-se as discrepâncias entre os métodos de avaliação. Como exemplo, os autores citam que, na utilização do método LEED $^{\mathrm{TM}}$, quando aplicado à avaliação da sustentabilidade em edificações inglesas, estas receberam uma classificação superior àquela auferida pelo método inglês BREEAM. Os autores concluem que, infelizmente, os métodos de avaliação não oferecem a possibilidade de comparação, uma vez que os focos são diferentes. Afirmam, ainda, que essas diferenças constituem barreiras a serem ultrapassadas na busca pela construção sustentável e complementam a discussão sugerindo o estabelecimento de metas globais para a avaliação de edificações, sem desconsiderar as características ambientais específicas de cada país.

\begin{tabular}{|l|l|}
\hline \multirow{4}{*}{ Temas ambientais } & \multicolumn{1}{|c|}{ Subtemas } \\
\cline { 2 - 2 } & Evitar poluição \\
\cline { 2 - 2 } & Proteção e melhoria da biodiversidade \\
\cline { 2 - 2 } & Melhoria de eficiência energética \\
\cline { 2 - 2 } Temas sociais & Uso eficiente de recursos \\
\cline { 2 - 2 } & Respeito à equipe de funcionários \\
\cline { 2 - 2 } & Relacionamento com comunidades locais \\
\cline { 2 - 2 } & Estabelecimento de parcerias \\
\hline \multirow{4}{*}{ Temas econômicos } & Aumento de produtividade e lucro \\
\cline { 2 - 2 } & Melhoria no projeto (produto oferecido) \\
\cline { 2 - 2 } & Monitoramento e relato de desempenho versus metas \\
\hline
\end{tabular}

Quadro 1 - Temas-chave para a construção sustentável

Fonte: adaptado de Construction Industry Research and Information Association (2001² apud SILVA, 2007).

\footnotetext{
${ }^{1}$ CONSTRUCTION INDUSTRY RESEARCH AND INFORMATION ASSOCIATION. Sustainable Construction: company indicators. London: CIRIA/WS Atkins Consultants, 2001. CIRIA Report C563 (CIRIA's Project RP609).

${ }^{2}$ Idem.
} 


\begin{tabular}{|l|c|c|c|}
\hline \multicolumn{1}{|c|}{ Critério } & BREEAM & HQE® & LEED $^{\text {TM }}$ \\
\hline Energia & $\mathrm{X}$ & $\mathrm{X}$ & $\mathrm{X}$ \\
\hline Emissão de CO2 & $\mathrm{X}$ & $\mathrm{X}$ & \\
\hline Ecologia & $\mathrm{X}$ & $\mathrm{X}$ & $\mathrm{X}$ \\
\hline Economia & & $?$ & \\
\hline Saúde e bem-estar & $\mathrm{X}$ & $\mathrm{X}$ & \\
\hline Qualidade do ar interior & $\mathrm{X}$ & $\mathrm{X}$ & $\mathrm{X}$ \\
\hline Inovação & $\mathrm{X}$ & $?$ & $\mathrm{X}$ \\
\hline Implantação no terreno & $\mathrm{X}$ & $\mathrm{X}$ & $\mathrm{X}$ \\
\hline Gerenciamento & $\mathrm{X}$ & $?$ & \\
\hline Materiais & $\mathrm{X}$ & $?$ & \\
\hline Poluição & $\mathrm{X}$ & $\mathrm{X}$ & $\mathrm{X}$ \\
\hline Tecnologias renováveis & $\mathrm{X}$ & $?$ & $\mathrm{X}$ \\
\hline Transporte & $\mathrm{X}$ & $?$ & $\mathrm{X}$ \\
\hline Desperdício & $\mathrm{X}$ & $\mathrm{X}$ & \\
\hline Água & $\mathrm{X}$ & $\mathrm{X}$ & $\mathrm{X}$ \\
\hline
\end{tabular}

\section{Quadro 2 - Comparação entre BREEAM, LEED ${ }^{m}$ e HQE ${ }^{\circledR}$}

Fonte: Salgado (2011) e adaptado de Reed et al. (2009, tradução nossa).

De maneira geral, entende-se que a principal vantagem das ferramentas e dos métodos de avaliação reside na orientação aos empreendedores, projetistas e construtores quanto aos aspectos a serem considerados na produção de edificações sustentáveis. Neste particular, tem destaque o método GREEN GLOBES (2011), que se constitui em um protocolo de avaliação on-line interativo, permitindo o reconhecimento de atributos ambientais do projeto de uma edificação. Esse método teve sua origem no sistema BREEAM, tendo sido desenvolvido por pesquisadores canadenses. Atualmente vem sendo adotado nas obras realizadas pelo governo daquele país.

No Brasil, apenas recentemente as construtoras se interessaram pela avaliação ambiental de seus projetos. Entre os métodos estrangeiros citados, o LEED $^{\text {TM }}$ foi o primeiro a ser adotado pelas empresas brasileiras, com a certificação, em 2007, de uma agência bancária, localizada na Granja Viana em São Paulo (GREEN..., 2012). O primeiro empreendimento a receber o certificado Aqua no Brasil foi uma loja localizada em Niterói (Rio de Janeiro), em 2009 (FUNDAÇÃO..., 2012).

Entre os métodos brasileiros que buscam estimular a qualidade ambiental das edificações, cita-se a proposta apresentada pela Caixa Econômica Federal, em 2010: o Selo Azul. Este selo se aplica a todos os tipos de projetos de empreendimentos habitacionais propostos à Caixa para financiamento, ou nos programas de repasse. O método consiste em verificar, durante a análise de viabilidade técnica do empreendimento, o atendimento aos 53 critérios de avaliação estabelecidos, distribuídos em seis categorias que orientam a classificação do projeto. Cabe destacar os requisitos relacionados às Práticas Sociais, que constituem 11 dos requisitos apresentados na proposta, sendo três de caráter obrigatório: a educação para a gestão de RCD (resíduos de construção e demolição); a educação ambiental dos empregados; e a orientação aos moradores (JOHN; RACINE, 2010).

Finalmente, cabe destacar o programa de Etiquetagem de Eficiência Energética de Edificações (ELETROBRAS; PROCEL, 2010), uma proposta também elaborada considerando-se a realidade brasileira, que se diferencia das demais por não constituir, especificamente, um método para auxílio ao projeto com qualidade ambiental, mas uma proposta de certificação das edificações que apresentem desempenho energético satisfatório, considerando requisitos estabelecidos. $\mathrm{O}$ processo de etiquetagem ocorre de forma distinta para edifícios comerciais, de serviços, públicos e residenciais. A etiqueta é concedida em dois momentos: na fase de projeto e após a construção do edifício. Nos edifícios residenciais são avaliados a envoltória, o sistema de aquecimento de água e os sistemas presentes nas áreas comuns dos edifícios (iluminação, elevadores, bombas centrífugas, etc.).

Os requisitos destinados à produção de edificações que considerem os princípios da qualidade ambiental podem ser divididos em técnicos e organizacionais. Nos métodos de auxílio ao projeto que foram apresentados, de maneira geral, destacam-se os aspectos relacionados com a qualidade ambiental do produto-edificação em todo o ciclo - que se estende desde o planejamento e o projeto até a fase de demolição. Existem, no entanto, questões organizacionais relacionadas com as práticas adotadas no dia a dia das empresas que também precisam ser analisadas e adaptadas, para que os profissionais possam atender 
positivamente às demandas do projeto integrado fundamental para a construção sustentável.

\section{Novos desafios para o desenvolvimento de projetos}

De acordo com Castells (2010), o desenvolvimento de projetos que consideram os princípios da alta qualidade ambiental preconizados pelo método HQE® pode ser dividido em duas etapas distintas, sendo a primeira a de definição de parâmetros, e a seguinte, efetivamente, a de concepção projetual. Ou seja, os profissionais envolvidos na concepção do projeto devem contar com o apoio dos especialistas, nas áreas específicas referentes aos alvos propostos pelo método. Esses especialistas serão os responsáveis pela realização da analise ambiental prévia, que, efetivamente, indicará os aspectos a serem considerados pelo projeto de arquitetura.

A primeira fase, de definição de parâmetros, pode ser dividida em duas etapas (CASTELLS, 2010):

(a) estudo do potencial ambiental do terreno com o auxílio dos parâmetros definidos pelo método $\mathrm{HQE}^{\circledR}$; e

(b) pré-programação $\mathrm{HQE}^{\circledR}$ - com a hierarquização dos 14 alvos definidos pela metodologia.

Esse mesmo autor acrescenta que o produto final da fase de definição de parâmetros pode ser, entre outros documentos, a apresentação de um caderno de exigências - onde os alvos do $\mathrm{HQE}^{\circledR}$ são priorizados - e um caderno de recomendações arquiteturais e urbanas, a serem consideradas pelos profissionais na concepção do projeto. Dessa forma, pode-se inferir que as decisões ligadas ao desempenho ambiental da edificação (estabelecimento das metas a serem atingidas) devem ocorrer anteriormente às decisões projetuais. A compreensão dessa questão somente se torna possível a partir do reconhecimento da existência de dois grupos de requisitos, a serem considerados pelo projeto:

(a) aqueles relacionados ao seu uso e ocupação, portanto, aos desejos e expectativas dos usuários; e

(b) aqueles relacionados com suas metas ambientais, ou seja, com o desempenho ambiental da edificação (as "necessidades ambientais" da edificação).

O potencial para atender a um ou mais alvos definidos pela metodologia será mais ou menos forte, dependendo da etapa do processo do projeto que se esteja realizando. Segundo Platzer (2009, tradução nossa), o ciclo de vida da edificação pode ser dividido em seis etapas:

(a) elaboração do programa do empreendimento que pode ser dividido entre as necessidades ambientais e as necessidades de projeto (usuários);

(b) desenvolvimento do(s) projeto(s);

(c) definição dos métodos executivos;

(d) execução da obra;

(e) uso, operação e manutenção da edificação; e

(f) demolição.

O Quadro 3 apresenta a relação entre cada uma dessas etapas e as metas referentes aos 14 ciclos da metodologia $\mathrm{HQE}^{\circledR}$ (Alta Qualidade Ambiental).

Conforme se pode observar analisando o Quadro 3 , a fase de desenvolvimento dos projetos é a que oferece o maior potencial para a obtenção de níveis ótimos no desempenho ambiental das edificações. Daí a importância de se aprimorar o processo de projeto, viabilizando a interoperabilidade entre os atores que fazem parte dele na realização do projeto completo da edificação. $O$ que se impõe aos profissionais de arquitetura e engenharia é a necessidade de se estabelecer um novo método de organização e gestão do processo de realização do projeto e construção que viabilize a incorporação dos princípios da sustentabilidade. Essa hipótese, por sua vez, desdobra-se em duas vertentes:

(a) a questão propriamente da organização das empresas que desenvolvem projetos, para viabilizar a incorporação dos requisitos de qualidade ambiental; e

(b) a questão da interoperabilidade entre as decisões de projeto, com destaque para o papel das tecnologias de informação e comunicação na arquitetura, engenharia e construção.

\section{Gestão da qualidade do processo para a garantia da qualidade ambiental do produto}

A preocupação com a organização das empresas ganhou maior enfoque a partir da publicação das normas de gestão da qualidade ISO 9001 (INTERNATIONAL..., 2008). A adoção dos requisitos estabelecidos por essa norma pelas empresas de construção civil (tanto de projetos, quanto do setor de execução de obras), foi e ainda é um processo lento, pois esbarra na principal crítica: a certificação da qualidade do processo não garante a qualidade do produto. 


\begin{tabular}{|c|c|c|c|c|c|c|c|}
\hline $\begin{array}{l}\text { CICLOS DA } \\
\text { METODOLOGIA } \\
\text { HQE® }\end{array}$ & $\underset{\text { Fases do ciclo de produção/vida da edificação }}{\longrightarrow}$ & 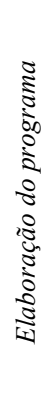 & 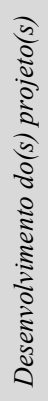 & 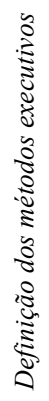 & 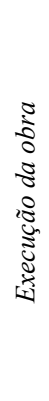 & 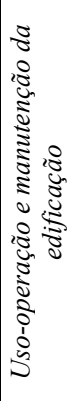 & 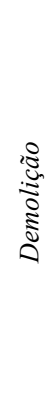 \\
\hline \multirow{2}{*}{$\begin{array}{l}1 \text { Relação harmoniosa } \\
\text { com o entorno } \\
\text { imediato }\end{array}$} & $\begin{array}{l}\text { Avaliação das vantagens e desvantagens do contexto } \\
\text { considerando a função do edifício, as necessidades dos } \\
\text { usuários e as demandas da vizinhança }\end{array}$ & $\mathrm{X}$ & $\mathrm{X}$ & & & & \\
\hline & $\begin{array}{l}\text { Leiaute que ofereça conforto e esteja em harmonia com o } \\
\text { sistema de transporte }\end{array}$ & & $X$ & & & & \\
\hline \multirow{3}{*}{$\begin{array}{l}2 \text { Escolha integrada } \\
\text { dos processos } \\
\text { construtivos }\end{array}$} & Adaptabilidade e durabilidade da edificação & $\mathrm{X}$ & $\mathrm{X}$ & & & & \\
\hline & Escolha integrada dos sistemas construtivos & & $\mathrm{X}$ & & $\mathrm{X}$ & & $\mathrm{X}$ \\
\hline & Escolha dos materiais de construção & & & $\mathrm{X}$ & $\mathrm{X}$ & & \\
\hline \multirow{5}{*}{$\begin{array}{l}3 \text { Canteiro de baixo } \\
\text { impacto ambiental }\end{array}$} & $\begin{array}{l}\text { Preparação do canteiro limitando a produção de rejeitos e } \\
\text { otimizando sua gestão }\end{array}$ & & & $\mathrm{X}$ & & & \\
\hline & Gestão diferenciada e valorização dos resíduos no canteiro & & & $\mathrm{X}$ & $\mathrm{X}$ & & \\
\hline & Redução dos ruídos e da poluição & & & & $\mathrm{X}$ & & \\
\hline & Gestão dos recursos - água e energia & & & & $\mathrm{X}$ & & \\
\hline & $\begin{array}{l}\text { Possibilidade de demolição que permita a reutilização dos } \\
\text { materiais }\end{array}$ & & & & $\mathrm{X}$ & & \\
\hline \multirow{2}{*}{4 Gestão da energia } & Redução do consumo de energia primária não renovável & $\mathrm{X}$ & $\mathrm{X}$ & & & $\mathrm{X}$ & \\
\hline & Gestão da poluição & $\mathrm{X}$ & $\mathrm{X}$ & & & $\mathrm{X}$ & \\
\hline \multirow{3}{*}{5 Gestão da água } & Economia da água potável & $\mathrm{X}$ & $\mathrm{X}$ & & & $\mathrm{X}$ & \\
\hline & Gestão das águas pluviais & $\mathrm{X}$ & $\mathrm{X}$ & & & & \\
\hline & Gestão das águas usadas (águas cinza) & & $\mathrm{X}$ & & & & \\
\hline \multirow{4}{*}{$\begin{array}{l}6 \text { Gestão dos rejeitos } \\
\text { das atividades }\end{array}$} & Gestão da produção dos rejeitos & & & & & $\mathrm{X}$ & \\
\hline & Adequação entre a coleta interna e a externa & & $\mathrm{X}$ & & & & \\
\hline & Gestão da triagem (seleção) dos rejeitos & $\mathrm{X}$ & $\mathrm{X}$ & & & $\mathrm{X}$ & \\
\hline & Otimização do sistema de coleta interna & $\mathrm{X}$ & $\mathrm{X}$ & & & & \\
\hline \multirow{4}{*}{$\begin{array}{l}7 \text { Gestão da } \\
\text { manutenção e } \\
\text { conservação }\end{array}$} & Otimização da necessidade de manutenção & & $\mathrm{X}$ & & & & \\
\hline & $\begin{array}{l}\text { Gestão dos efeitos negativos dos produtos e processos } \\
\text { relacionados à manutenção }\end{array}$ & & $\mathrm{X}$ & & $\mathrm{X}$ & $\mathrm{X}$ & \\
\hline & $\begin{array}{l}\text { Facilidade de acesso para realização da manutenção e } \\
\text { simplicidade nas operações }\end{array}$ & & $\mathrm{X}$ & & & & \\
\hline & $\begin{array}{l}\text { Adoção de equipamentos para manutenção do desempenho } \\
\text { na fase de uso e operação }\end{array}$ & & & $\mathrm{X}$ & & $\mathrm{X}$ & \\
\hline
\end{tabular}

Quadro 3 - Relação entre os requisitos do HQE® e as etapas do ciclo de vida da edificação

Fonte: adaptado de Platzer (2009, tradução nossa). 


\begin{tabular}{|c|c|c|c|c|c|c|c|}
\hline $\begin{array}{l}\text { CICLOS DA } \\
\text { METODOLOGIA HQE }\end{array}$ & $\underset{\text { Fases do ciclo de produção /vida da edificação }}{\longrightarrow}$ & 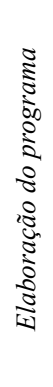 & $\begin{array}{l}5 \\
0 \\
0 \\
0 \\
0 \\
\vdots \\
0 \\
5 \\
0 \\
0 \\
0 \\
\vdots \\
\vdots \\
\vdots \\
\vdots \\
0 \\
\vdots \\
0 \\
0 \\
0 \\
0\end{array}$ & 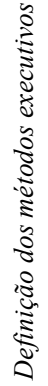 & 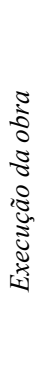 & 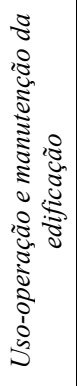 & 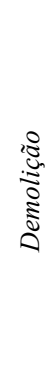 \\
\hline \multirow{3}{*}{8 Conforto higrotérmico } & $\begin{array}{l}\text { Criação de condições de conforto no inverno e } \\
\text { meia-estação }\end{array}$ & & $\mathrm{X}$ & & & $X$ & \\
\hline & $\begin{array}{l}\text { Criação de condições de conforto no verão em } \\
\text { edificações não climatizadas }\end{array}$ & & $\mathrm{X}$ & & & $\mathrm{X}$ & \\
\hline & $\begin{array}{l}\text { Criação de condições de conforto no verão em } \\
\text { edificações climatizadas }\end{array}$ & & & & & $\mathrm{X}$ & \\
\hline \multirow{4}{*}{9 Conforto acústico } & $\begin{array}{l}\text { Adoção de soluções que favoreçam o conforto } \\
\text { acústico }\end{array}$ & $\mathrm{X}$ & $\mathrm{X}$ & & & & \\
\hline & $\begin{array}{l}\text { Adoção de soluções que favoreçam o isolamento } \\
\text { acústico }\end{array}$ & & $\mathrm{X}$ & $\mathrm{X}$ & & & \\
\hline & $\begin{array}{l}\text { Adoção de soluções que favoreçam a correção } \\
\text { acústica, onde necessária }\end{array}$ & & & & & $\mathrm{X}$ & \\
\hline & Proteção contra o ruído dos usuários e vizinhos & $\mathrm{X}$ & & & & & \\
\hline \multirow{4}{*}{10 Conforto visual } & $\begin{array}{l}\text { Uso eficiente da iluminação natural, evitando os } \\
\text { inconvenientes (ofuscamento) }\end{array}$ & $\mathrm{X}$ & $\mathrm{X}$ & & & & \\
\hline & $\begin{array}{l}\text { Concepção de iluminação artificial que atenda às } \\
\text { necessidades de conforto }\end{array}$ & & $\mathrm{X}$ & $\mathrm{X}$ & & & \\
\hline & $\begin{array}{l}\text { Estabelecimento de uma relação visual satisfatória } \\
\text { com o exterior }\end{array}$ & $\mathrm{X}$ & $\mathrm{X}$ & & & & \\
\hline & $\begin{array}{l}\text { Concepção de iluminação artificial das zonas } \\
\text { externas (acessos, calçadas) que sejam confortáveis } \\
\text { e garantam a segurança dos usuários }\end{array}$ & & $\mathrm{X}$ & $\mathrm{X}$ & & & \\
\hline \multirow{2}{*}{11 Conforto olfativo } & Redução das fontes de odores desagradáveis & & & $\mathrm{X}$ & & & \\
\hline & Limitação dos odores desagradáveis & & $\mathrm{X}$ & & & $\mathrm{X}$ & \\
\hline \multirow{2}{*}{$\begin{array}{l}12 \text { Qualidade sanitária } \\
\text { dos espaços }\end{array}$} & $\begin{array}{l}\text { Limitação das interferências entre os espaços } \\
\text { interiores }\end{array}$ & & & $\mathrm{X}$ & & & \\
\hline & $\begin{array}{l}\text { Criação de boas condições de higiene, } \\
\text { especialmente para os equipamentos coletivos }\end{array}$ & & & & & $\mathrm{X}$ & \\
\hline \multirow{2}{*}{$\begin{array}{l}13 \text { Qualidade sanitária } \\
\text { do ar }\end{array}$} & Gestão das fontes de poluição & & $\mathrm{X}$ & $\mathrm{X}$ & & & \\
\hline & Limitação dos efeitos dos poluentes aéreos na saúde & $\mathrm{X}$ & $\mathrm{X}$ & & & $\mathrm{X}$ & \\
\hline \multirow{3}{*}{$\begin{array}{l}14 \text { Qualidade sanitária } \\
\text { da água }\end{array}$} & $\begin{array}{l}\text { Adoção de soluções que favoreçam a qualidade da } \\
\text { água destinada ao consumo humano fornecida pelo } \\
\text { sistema predial }\end{array}$ & & & $\mathrm{X}$ & & $\mathrm{X}$ & \\
\hline & $\begin{array}{l}\text { Adoção de soluções que permitam o controle do } \\
\text { acesso aos reservatórios de distribuição da água }\end{array}$ & & & & & $\mathrm{X}$ & \\
\hline & $\begin{array}{l}\text { Gestão da qualidade da água que não seja } \\
\text { proveniente de uma rede de distribuição de água } \\
\text { potável }\end{array}$ & & & & & $\mathrm{X}$ & \\
\hline
\end{tabular}

Quadro 3 - Relação entre os requisitos do HQE® e as etapas do ciclo de vida da edificação (continuação)

Fonte: adaptado de Platzer (2009, tradução nossa).

Sobre esse assunto, Platzer (2009) comenta que o surgimento dessa norma, na década de 1990, trouxe muita discussão entre os profissionais, porque se constituía em mais um instrumento regulamentador que, na opinião deles, não traria nenhuma contribuição para a melhoria da qualidade das edificações.

Por outro lado, os profissionais compreenderam a afinidade existente entre as exigências dos projetos com alta qualidade ambiental e os requisitos da norma de gestão ambiental ISO 14000. Isso porque, de maneira geral, as diferentes metodologias para auxílio ao desenvolvimento de projetos com alta qualidade ambiental consideram importantes não apenas a análise dos critérios técnicos relacionados com o projeto como também os mecanismos de gestão que dão suporte à realização do projeto da edificação.

Entre os esforços para auxiliar o setor de projetos na organização das empresas para a realização de 
projetos com qualidade ambiental, destaca-se o referencial QUALIPROM ${ }^{\circledR}$. Elaborado pela parceria entre AFAQ AFNOR, Fédération des Promoteurs Constructeurs de France e CERTIVEA, esse referencial se aplica a um promotor/construtor que deseja (REFERENTIAL..., 2002):

(a) integrar as metas do $\mathrm{HQE}^{\circledR}$ em todas as suas operações; e

(b) demonstrar sua capacidade para prestar o serviço, de forma a atender às necessidades de clientes e partes interessadas, em conformidade com os requisitos regulamentares aplicáveis, e respondendo à demanda ambiental.

Essa metodologia se baseia nas exigências da norma ISO 9001 (INTERNATIONAL..., 2008) e, também, nas orientações dadas pelo processo $\mathrm{HQE}^{\circledR}$, no que se refere à compatibilização das soluções para a realização de projetos, conforme esse referencial.

Ressalta-se que o aspecto fundamental para a realização de projetos com alta qualidade ambiental é a integração das decisões projetuais. Portanto, será fundamental definir mecanismos e procedimentos que permitam a troca de informações (interoperabilidade) entre os profissionais durante a realização dos projetos.

\section{Interoperabilidade: fator preponderante na realização do projeto da edificação sustentável}

A questão da interoperabilidade nas empresas de construção civil vem suscitando várias discussões. Pouchard e Cutting-Decelle (2007) definem a interoperabilidade como a habilidade de um sistema ou produto de funcionar junto a outros sistemas ou produtos, sem a necessidade de um esforço especial por parte do operador.

Em 2004, o NIST elaborou um levantamento sobre os custos gerados pela falta de interoperabilidade na indústria da construção civil e estimou uma carga de custos anuais de 15,8 bilhões de dólares. De acordo com Chapman (2005), os custos aumentam consideravelmente conforme se passa da fase de projeto para a fase de execução da obra, e estariam relacionados com o retrabalho, gerado pela necessidade de reintroduzir os dados do projeto manualmente, e com a verificação e ajustes, a serem realizados na própria obra.

Esse levantamento suscitou o interesse dos pesquisadores franceses, que, em 2010, publicaram os resultados obtidos com a pesquisa sobre os custos gerados pela falta de interoperabilidade na indústria da construção civil no seu país. Entre os depoimentos dados pelas empresas francesas que participaram da pesquisa destacam-se os seguintes (FERRIES, 2010, tradução e grifos nossos):

(c) a interoperabilidade é um problema pequeno que esconde problemas extremamente dispendiosos;

(d) se as empresas ainda não reconhecem a importância da interoperabilidade, certamente todos reconhecem que viabilizar a comunicação entre os atores envolvidos no processo é uma prioridade; $\mathrm{e}$

(e) usamos uma metodologia de trabalho inadequada para as atividades a serem desenvolvidas. Há que se repensar o processo, bem como reavaliar as competências necessárias à realização do trabalho, lembrando que as competências ficam comprometidas pela inadequação dos processos.

Os resultados obtidos com esse levantamento indicaram que os custos das empresas francesas, com a falta da interoperabilidade adequada, foram duas vezes superiores quando comparados aos custos das empresas norte-americanas. De acordo com Ferries (2010), para se obterem resultados ainda mais precisos, seria necessário analisar o processo de projeto como um todo.

Até pouco tempo atrás, a tecnologia da informação e os softwares disponíveis não ofereciam soluções que viabilizassem a interoperabilidade entre os profissionais durante o processo de projeto da indústria da construção civil (produção de edificações). Entretanto, o surgimento do IFC (Industry Foundation Classes) mudou essa realidade. O IFC consiste em um conjunto abstrato de metadados ou de regras que definem os elementos, seus tipos, atributos e relacionamentos que podem ser estabelecidos na construção de um modelo. Ele foi projetado para facilitar a interoperabilidade entre todas as informações relacionadas à construção, estendendo-se por todo o ciclo de vida da edificação, facilitando a cooperação entre os diferentes especialistas de projeto e contribuindo para racionalizar os métodos de trabalho. Segundo Ferries (2009), o IFC se constitui na base dos softwares que viabilizam a modelagem digital das edificações em inglês, BIM (Building Information Modelling).

Naturalmente, o compartilhamento de informações através de um modelo digital implica a organização do processo de trabalho entre os atores envolvidos na produção do projeto. Estes deverão rever sua organização interna, de forma a buscar um modo de trabalho que seja comum a todos, viabilizando a interoperabilidade e o trabalho sobre os mesmos dados: elementos 
topográficos, projetos de arquitetura, memoriais descritivos, orçamento, entre outros (FERRIES, 2009).

Fica evidente, portanto, que no momento em que o setor de projetos se deparou com o desafio da sustentabilidade - que demanda a estruturação de um sistema de decisões que possa garantir a realização do projeto de forma integrada - a discussão sobre a gestão do processo de projeto foi intensificada. A realização de um projeto com alta qualidade ambiental implica a integração entre as decisões projetuais e, consequentemente, a integração entre os profissionais das diferentes especialidades de projeto. Essa integração, por sua vez, implica uma revisão dos procedimentos de trabalho normalmente adotados pelas empresas de projeto, acostumadas ao processo linear e sequencial, que não mais atende às exigências do projeto para uma edificação sustentável.

\section{Pesquisa junto às empresas de projeto: metodologia adotada}

A construção sustentável depende da revisão das práticas adotadas na construção civil, desde a fase de realização do projeto, que, conforme destacado anteriormente, se constitui na fase mais impactante, até a seleção dos métodos executivos, a organização do canteiro de obras e a gestão da construção.

$\mathrm{Na}$ França, a partir da preocupação com o desempenho energético das edificações, os profissionais começaram a repensar o processo de projeto e construção. A metodologia $\mathrm{HQE}^{\circledR}$ é uma das que vêm sendo consideradas na realização dos projetos das edificações daquele país, sendo uma exigência nas concorrências públicas.

A partir do interesse nas práticas adotadas para o desenvolvimento de projetos conforme esse método, realizou-se uma pesquisa de campo junto aos profissionais que atuam em empresas com relevante atuação na França. Entre as questões a serem investigadas destacam-se:

(a) conhecer as principais dificuldades desse método de auxílio ao projeto;

(b) identificar se o método $\mathrm{HQE}^{\circledR}$ se constitui, de fato, no mais eficiente em termos de construção sustentável; e

(c) analisar os aspectos de gestão de projeto que podem auxiliar na realização do projeto para a edificação sustentável.

Conforme esclarecido anteriormente, a escolha da França como país para a realização desta pesquisa se justificou pelo fato de ser o país de origem do método $\mathrm{HQE}^{\circledR}$ - Haute Qualité Environmentale (Alta Qualidade Ambiental) -, que foi trazido para o Brasil por pesquisadores da Universidade de São Paulo (USP), dando origem ao método de certificação brasileiro Aqua (Alta Qualidade Ambiental).

$\mathrm{Na}$ pesquisa realizada, procurou-se identificar a opinião não apenas em relação ao método $\mathrm{HQE}^{\circledR}$, mas também quanto à construção sustentável na França, de maneira geral. Os entrevistados também foram questionados sobre as possíveis modificações incorporadas ao seu processo de projeto, em decorrência das exigências do projeto das edificações com alta qualidade ambiental. As etapas dessa investigação incluíram:

(a) seleção da(s) empresa(s), para a realização das entrevistas;

(b) elaboração do instrumento, para orientar a entrevista;

(c) realização da pesquisa de campo; e

(d) interpretação dos dados obtidos e cruzamento das informações.

Como forma de auxiliar a realização da entrevista, adotou-se um roteiro com as seguintes questões:

$1^{\text {a }}$ Questão - Qual a sua visão sobre a construção sustentável na França?

$2^{\text {a }}$ Questão - Qual a sua opinião sobre a certificação francesa $\mathrm{HQE}^{\circledR}$ ?

$3^{\text {a }}$ Questão - Sobre a organização gerencial da empresa.

3.1 - Acredita que a organização do trabalho seja um aspecto importante para a realização de uma arquitetura que considere os princípios de desenvolvimento sustentável? (Se a resposta for positiva, responder à questão seguinte.)

3.2 - Incorporou alguma modificação dentro da sua empresa e seu processo de trabalho para melhor atender às exigências do projeto para produção de edificações sustentáveis? Quais?

$4^{\mathrm{a}}$ Questão - Sobre a utilização de softwares BIM.

4.1 - Conhece algum software que trabalha com a linguagem IFC (BIM)? (Se a resposta for positiva, responder à questão seguinte.).

4.2 - Acredita que a utilização de softwares BIM auxilia a produção de edificações sustentáveis? Por quê? 
Ressalta-se que os entrevistados puderam se expressar de forma livre durante as entrevistas, expondo suas ideias muito além das questões colocadas neste roteiro.

\section{Considerações preliminares}

Antes de apresentar os resultados obtidos com a pesquisa, considera-se importante apresentar o contexto de trabalho dos arquitetos, que, na França, se diferencia bastante das práticas adotadas no Brasil. Essa diferença tem início na formação profissional, considerando que, para atuar como responsável pelos seus próprios projetos, o arquiteto francês precisa, após a conclusão dos seus estudos superiores, realizar uma complementação na sua formação profissional, com duração de um ano, chamada HMONP (Habilitation de l'architecte diplômé d'Etat à exercer la Maîtrise d'Euvre en son Nom Propre), cuja tradução seria Habilitação ao Arquiteto Diplomado para Exercer a Arquitetura em seu Próprio Nome. Para a obtenção desse título é requerida a defesa de um projeto final, diante de um júri específico. A Ordem dos Arquitetos disponibiliza um documento próprio orientando os objetivos do júri do HMONP, bem como aspectos a serem considerados no momento da avaliação.

$O$ objetivo dessa formação é permitir aos candidatos adquirir, expandir ou atualizar e aplicar seus conhecimentos em três áreas fundamentais: responsabilidade profissional, custos do projeto e construção, e legislação profissional e da construção. A formação conta com a participação de um supervisor dos estudos $e$ de um profissional que atua como tutor e que pertença à empresa onde o candidato aplicará os conhecimentos que procurou adquirir durante o período de formação. (CONSEIL..., 2010, p. 13, tradução nossa).

Também, diferentemente do que ocorre no Brasil, ao projeto que se pretende aprovar, na França, é necessário anexar um parecer circunstanciado dos consultores das especialidades (térmica, acústica, lumínica). Dessa forma, o projeto, antes de ser encaminhado para aprovação, passa pela avaliação não apenas da empresa autora do projeto - que deverá considerar as exigências referentes à ocupação do solo, soluções arquitetônicas, desempenho ambiental, entre outros aspectos específicos -, mas também dos escritórios de consultoria (térmica, acústica, iluminação, outros), que deverão emitir um parecer sobre os sistemas, que garantirão o adequado funcionamento da edificação.

Essa informação é fundamental para a compreensão dos resultados aqui apresentados, uma vez que as respostas dadas pelas empresas de consultoria algumas vezes divergem daquelas apresentadas pelos escritórios de arquitetura.

\section{Caracterização das empresas}

As entrevistas foram realizadas no segundo semestre de 2010, quando foram visitadas oito empresas:

(a) quatro escritórios de arquitetura; duas empresas de consultoria; e

(b) duas grandes empresas construtoras.

As empresas estão caracterizadas no Quadro 4.

Os critérios para seleção das empresas foram:

(a) atuação no desenvolvimento de projetos e/ou obras de arquitetura e engenharia;

(b) número de funcionários superior a 15 profissionais;

(c) parceria com o Laboratoire de Recherche Architectural (Laboratório de Pesquisa em Arquitetura) da École Nationale Superiéure D'Architecture de Toulouse, onde a pesquisa foi desenvolvida;

(d) reconhecimento, no mercado da construção, pela realização de projetos que considerem os princípios da construção sustentável; e

(e) existência de sistema de gestão da qualidade implementado (não necessariamente certificado).

As empresas visitadas tinham sede em Toulouse, e algumas com representações em Paris e outras cidades francesas (empresas A, D, E, F, G e H), e também fora da França (empresas E, G e H), em países como China, Marrocos, Bélgica e Reino Unido.

\section{Resultados obtidos com a pesquisa}

As entrevistas ocorreram nas próprias empresas. Nas empresas B, C, D, E e F foi possível realizar a entrevista com os dirigentes das empresas (alta administração). Em três empresas (A, G e H) foram entrevistados os profissionais indicados pela direção dessas empresas para responder como seus representantes nesta pesquisa. 


\begin{tabular}{|c|c|c|c|c|}
\hline & Tipo da empresa & $\begin{array}{l}\text { Número de } \\
\text { funcionários }\end{array}$ & Área de atuação & $\begin{array}{c}\text { Certificado } \\
\text { ISO } 9001 \\
\text { (INTERNATIO } \\
\text { NAL..., 2008) } \\
\end{array}$ \\
\hline $\boldsymbol{A}$ & \multirow{4}{*}{$\begin{array}{l}\text { Escritórios de } \\
\text { arquitetura }\end{array}$} & 47 & $\begin{array}{l}\text { Projetos aeroportuários, hospitalares e de } \\
\text { equipamentos esportivos }\end{array}$ & $\operatorname{sim} * *(2011)$ \\
\hline$B$ & & n.i*. & Projetos de escritórios e habitações unifamiliares & não \\
\hline$C$ & & 16 & Projetos de escritórios e habitações unifamiliares & $\operatorname{sim}$ \\
\hline $\boldsymbol{D}$ & & 35 & $\begin{array}{l}\text { Projetos de prédios institucionais de maneira } \\
\text { geral, participação em concursos }\end{array}$ & não \\
\hline $\boldsymbol{E}$ & \multirow{2}{*}{$\begin{array}{l}\text { Empresas de } \\
\text { consultoria }\end{array}$} & n.i. $*$ & $\begin{array}{l}\text { Projetos de acústica arquitetônica, ambiental e } \\
\text { industrial }\end{array}$ & não \\
\hline $\boldsymbol{F}$ & & 34 & $\begin{array}{l}\text { Projetos de acústica arquitetônica, ambiental e } \\
\text { industrial e eólica }\end{array}$ & não \\
\hline $\boldsymbol{G}$ & \multirow[b]{2}{*}{$\begin{array}{l}\text { Construtoras e } \\
\text { incorporadoras }\end{array}$} & 1400 & $\begin{array}{l}\text { Planejamento, projeto e construção, inovação } \\
\text { industrial e engenharia civil }\end{array}$ & $\operatorname{sim}$ \\
\hline $\boldsymbol{H}$ & & 400 & $\begin{array}{l}\text { Planejamento, projeto, construção e fabricação de } \\
\text { elementos (pré-moldados de concreto), } \\
\text { incorporação e gerenciamento }\end{array}$ & $\operatorname{sim}$ \\
\hline
\end{tabular}

Quadro 4 - Caracterização das empresas visitadas

Nota: * Essas empresas não informaram o número exato.

**À época da entrevista a empresa estava em vias de obter a certificação ISO 9001 (INTERNATIONAL..., 2008), obtida em abril de 2011 .

\section{Respostas obtidas a partir das questões apresentadas}

\section{Com relação à construção sustentável na França e a certificação HQE®}

\section{Empresa A}

A representante da empresa ressaltou que, na França, devido ao grande número de regulamentos, alguns requisitos do $\mathrm{HQE}^{\circledR}$ já eram exigidos, o que tornou redundantes algumas exigências do método. Por outro lado, destacou que, embora a certificação $\mathrm{HQE}^{\circledR}$ possa orientar os arquitetos na proposição de soluções sustentáveis, a decisão de construir ainda é do empreendedor, que, efetivamente, paga pelos custos de produção do edifício. Ela considerava aquele momento difícil para o estabelecimento de uma cultura de construção sustentável, devido ao contexto, caracterizado por mudanças econômicas e, consequentemente, por profundas mudanças no mercado imobiliário francês.

\section{Empresa B}

$\mathrm{O}$ diretor da empresa $\mathrm{B}$ destacou as iniciativas francesas em torno da construção de cidades sustentáveis (villes durables ou eco quartiers). Mas, na sua opinião, existem muitas regras a serem modificadas para que o arquiteto francês possa, efetivamente, trabalhar dentro do espírito do desenvolvimento sustentável, pois, de acordo com seu depoimento, a legislação francesa ainda apresentaria alguns entraves.

$\mathrm{O}$ arquiteto se posicionou de forma contrária à obrigatoriedade da certificação $\mathrm{HQE}^{\circledR}$ e lembrou que esta não garante a qualidade da ambiência dos espaços edificados, mas considerava o método positivo, como orientação aos arquitetos, no sentido de se criar uma consciência ambiental. Ele acrescentou que o desenvolvimento sustentável não se limita a qualquer certificação. Na sua opinião, a certificação BREEAM inglesa seria melhor, quando comparada ao método francês $\mathrm{HQE}^{\circledR}$, porque permite maior liberdade aos arquitetos na definição das características do projeto.

\section{Empresa C}

A dirigente da empresa $\mathrm{C}$ acreditava que a conscientização para a construção sustentável ainda não estaria totalmente difundida na França. Seria necessária uma mudança na mentalidade dos empreendedores (clientes), uma vez que o projeto para a edificação sustentável (conforme sua opinião) possui um custo mais elevado, quando comparado ao projeto tradicional. Ela ressaltou, ainda, que existem diversos aspectos relacionados à produção do projeto da edificação sustentável que dependeriam da sensibilidade de cada profissional. Daí, entender que o atendimento à certificação $\mathrm{HQE}^{\circledR}$ não seja suficiente para garantir a produção de edificações sustentáveis.

\section{Empresa D}

$\mathrm{Na}$ opinião do arquiteto-chefe da empresa $\mathrm{D}$, nem todos os arquitetos franceses trabalhavam dentro dos princípios do desenvolvimento sustentável. Ele não via grandes diferenças entre as certificações $\mathrm{HQE}^{\circledR}$, BREEAM ou LEED, mas ressaltou que todas as concorrências públicas francesas exigem o atendimento ao método $\mathrm{HQE}^{\circledR}$. O cliente privado, por sua vez, nem sempre se interessa pela certificação ambiental porque, segundo sua opinião, 
o custo da produção da edificação sustentável é elevado.

\section{Empresa E}

De acordo com a opinião do engenheiro-chefe desta empresa, o edifício representa muito pouco em relação ao desenvolvimento sustentável. O mais importante seria trabalhar ao nível da cidade, das necessidades dos cidadãos (transporte público, facilidade de acesso, entre outros). Ele acrescentou que a principal diferença entre o projeto tradicional e o projeto $\mathrm{HQE}^{\circledR}$ consistia no fato de o segundo considerar, também, as atividades do canteiro de obras, particularmente no que se refere aos impactos no meio ambiente durante a execução (com destaque para o controle de ruídos).

$\mathrm{Na}$ sua opinião, as exigências do método $\mathrm{HQE}^{\circledR}$ não seriam suficientes para garantir a produção de edificações com o desempenho ambiental adequado, particularmente no que se refere ao conforto acústico. Segundo ele, as exigências do método são inferiores às efetivamente necessárias para garantir o desempenho adequado. Essa empresa trabalha com clientes que solicitam diferentes certificações (HQE ${ }^{\circledR}$, LEED, BREEAM). Ele considera que existe certa semelhança entre os dois métodos europeus, mas acredita que o método inglês BREEAM apresente requisitos e exigências mais precisos que o $\mathrm{HQE}^{\circledR}$.

\section{Empresa $\mathbf{F}$}

$\mathrm{Na}$ visão do engenheiro entrevistado, dirigente da empresa F, as certificações ambientais não apresentam nenhuma informação nova. A dificuldade reside na necessidade de se realizar o projeto integrado. Também acredita que a questãochave para a qualidade do projeto deva ser o interesse nas reais necessidades dos usuários, da vizinhança, da sociedade e, portanto, o conhecimento dos aspectos humanos seria preponderante às questões técnicas, já conhecidas pelos profissionais franceses.

Quanto ao método $\mathrm{HQE}^{\circledR}$, na sua opinião, existiriam duas questões: o método e a certificação. $\mathrm{O}$ método teria o seu aspecto positivo, porque poderia auxiliar os profissionais na realização do projeto sustentável. A certificação, por outro lado, apenas serviria para que o cliente pudesse demonstrar o bom uso dos recursos. Daí ser adotada pelas instituições públicas como forma de demonstrar o adequado uso do erário público.

\section{Empresa G}

Nessa empresa, a certificação BREEAM é a mais demandada pelos clientes porque, embora os objetivos das duas certificações (BREEAM e $\mathrm{HQE}^{\mathbb{B}}$ ) sejam (na sua opinião) praticamente os mesmos, a certificação inglesa possui reconhecimento internacional.

\section{Empresa $\mathrm{H}$}

$\mathrm{O}$ representante da empresa $\mathrm{H}$ destacou que, embora o $\mathrm{HQE}^{\circledR}$ seja uma exigência apenas para os clientes públicos, os investidores privados já começaram a se interessar pela certificação como forma de valorizar seu patrimônio, pois um imóvel que possui essa certificação teria maior liquidez (facilidade de revenda).

\section{Com relação à organização das empresas para a produção da edificação sustentável}

\section{Empresa A}

A organização do sistema de gestão desta empresa teve início a partir da demanda de um dos clientes. Desde o final dos anos 1990, a empresa já vinha registrando formalmente seus processos de trabalho (a certificação ISO 9001 (INTERNATIONAL..., 2008) ocorreu em 2011).

A profissional acrescentou que a mudança na organização da empresa deveu-se mais ao aumento no número de profissionais (à época da entrevista a empresa contava com a participação de cerca de quarenta e sete colaboradores) do que à realização de projetos considerando os princípios da construção sustentável. Por outro lado, ela acreditava que a certificação $\mathrm{HQE}^{\circledR}$ exige certo formalismo no processo de projeto, sendo necessária a organização de um sistema de gestão das informações para facilitar o atendimento aos requisitos propostos pela certificação.

\section{Empresa B}

A empresa B chegou a participar de uma iniciativa promovida pela Ordem dos Arquitetos (L'Ordre des Architectes), que reuniu empresas de projeto interessadas na certificação dos seus sistemas de gestão da qualidade, conforme os requisitos da norma de ISO 9001 (INTERNATIONAL..., 2008). Essa iniciativa não teve sucesso, e a maior parte das empresas de arquitetura desistiu. $\mathrm{Na}$ opinião do arquiteto, isso ocorreu porque grande parte dos escritórios de arquitetura na França são de pequeno porte (1 ou 2 arquitetos), e o sistema de gestão, organizado conforme a norma, seria considerado inadequado para essas pequenas empresas devido à quantidade de documentos e registros requeridos.

\section{Empresa C}

A dirigente dessa empresa também citou a iniciativa da Ordem dos Arquitetos, que reuniu empresas de projeto interessadas na certificação a norma ISO 9001 (INTERNATIONAL..., 2008), e confirmou o desinteresse da maior parte das empresas, que não estavam certas quanto aos benefícios que um sistema dessa natureza poderia 
trazer. Entretanto, ela destacou que foi a partir dessa iniciativa que a sua empresa deu início ao processo de organização do seu sistema de gestão da qualidade.

Na sua opinião, a principal desvantagem de um sistema de gestão da qualidade reside na grande quantidade de registros, que precisam ser preenchidos e controlados para garantir a validação das atividades. Ela ressaltou que, para realizar o projeto da edificação sustentável, a empresa de arquitetura precisaria se organizar, pois a quantidade de informações a serem consideradas no processo de projeto seria ainda maior, sendo necessário preparar a empresa para melhor atender o cliente que exige o cumprimento dos requisitos ambientais.

\section{Empresa D}

O diretor da empresa afirmou que, embora eles tenham iniciado a organização do sistema de gestão da qualidade da empresa conforme os requisitos da norma ISO 9001 (INTERNATIONAL..., 2008), decidiram não certificar, pois consideraram exagerada a quantidade de documentos e registros exigidos. Mesmo assim, de acordo como o seu depoimento, a empresa possuía um método de trabalho registrado e de conhecimento de todos os colaboradores.

Ele também considera que um sistema de gestão organizado pode ajudar o profissional na realização dos projetos de edificações que atendam aos requisitos de uma certificação ambiental, tal como o $\mathrm{HQE}^{\circledR}$.

\section{Empresa E}

Esta empresa chegou a buscar um profissional que pudesse organizar os procedimentos de trabalho, visando à certificação do sistema de gestão da qualidade conforme a norma ISO 9001 (INTERNATIONAL..., 2008). Entretanto, eles não conseguiram encontrar nenhum consultor que conhecesse o dia a dia de trabalho de uma empresa como essa (escritório de consultoria em acústica) e nem que tivesse experiência na organização de um sistema de gestão nesse tipo de organização. Por essa razão, desistiram da certificação. Entretanto, embora não seja certificada, a empresa possui um método de trabalho estabelecido formalmente.

\section{Empresa F}

À época da entrevista, essa empresa contava com a participação de trinta e cinco profissionais, e o principal entrave ao processo de trabalho, na visão do dono da empresa, era quanto à gestão da comunicação. Segundo ele, a empresa possuía alguns procedimentos de trabalho registrados formalmente, particularmente aqueles relacionados à parte administrativa da empresa. $\mathrm{O}$ processo de projeto, por sua vez, dependeria de cada cliente/projeto, não sendo possível generalizar os procedimentos.

\section{Empresa G}

A empresa G já possuía o certificado ISO 9001 (NTERNATIONAL)..., 2008) e, à época da realização desta pesquisa, estava em vias de obter a certificação ISO 14001 (INTERNATIONAL..., 2004). Na opinião do representante da empresa, a organização para a certificação da qualidade, já implantada e certificada, facilitou a complementação para o sistema de gestão ambiental, pois os profissionais já estavam acostumados a trabalhar conforme os procedimentos estabelecidos formalmente.

\section{Empresa $\mathrm{H}$}

A empresa H obteve a certificação ISO 9001 (INTERNATIONAL..., 2008) entre 1995 e 1998. De acordo com o representante, como a certificação $\mathrm{HQE}^{\circledR}$ é qualitativa, o fato de a empresa já estar organizada e certificada, conforme a norma de sistema de gestão da qualidade, facilitou a organização para atendimento aos requisitos ambientais, porque os profissionais (tal como na empresa G) já estavam acostumados a trabalhar cumprindo os procedimentos estabelecidos formalmente.

\section{Com relação à interoperabilidade na produção de edificações sustentáveis e à utilização de softwares BIM}

\section{Empresas A e C}

Nenhuma das duas trabalhava com softwares BIM à época das entrevistas.

\section{Empresa B}

De acordo com o depoimento, a empresa trabalha com um dos softwares que utilizam a lógica BIM, mas o entrevistado ainda via dificuldades na atuação de todos os profissionais ao mesmo tempo no mesmo projeto.

\section{Empresa D}

Esta empresa já trabalhava há dez anos com softwares que utilizam a lógica BIM, mas isso sempre foi uma dificuldade, uma vez que a maioria dos escritórios parceiros não utilizava todas as funcionalidades e possibilidades oferecidas por esses softwares. Em decorrência desse fato, os projetos elaborados em BIM acabavam sendo convertidos para o software utilizado pelos parceiros.

Mesmo assim, ele destacou as vantagens no uso do software BIM, especialmente na fase de concepção arquitetônica, quando as diferentes variáveis de 
projeto podem ser compatibilizadas desde o início do processo. Além disso, os softwares BIM possuem interface com outros softwares que permitem a simulação do desempenho das edificações.

\section{Empresa E}

O dirigente desta empresa acredita no potencial dos softwares BIM na realização de projetos com qualidade ambiental. Por esse motivo, a empresa, inclusive, participou de um projeto em parceria com a l'Ecole Nationale d'Architecture ${ }^{3}$, onde os projetos de edificações existentes foram submetidos a simulações que permitiram a avaliação do seu desempenho técnico (no caso, essa empresa era responsável pela avaliação do desempenho acústico).

\section{Empresa $\mathrm{F}$}

$\mathrm{O}$ diretor da empresa $\mathrm{E}$ entendia as vantagens de um software que viabilize a integração das decisões de projeto. Na sua opinião, mais importante seria permitir que os profissionais pudessem trabalhar em conjunto. Ele afirmou que, embora os softwares possibilitem a integração de soluções, para gerar inovação seria necessário que os profissionais pudessem discutir pessoalmente as diferentes possibilidades e soluções em relação ao projeto. Além disso, argumentou quanto à necessidade de se estabelecer um método para controle das versões. Conforme seu depoimento:

Se todos os profissionais estiverem trabalhando simultaneamente e realizando modificações no mesmo projeto, como será possível saber qual a última versão?

Outra questão levantada pelo diretor dessa empresa foi com relação à questão técnica. Um software capaz de integrar todos os sistemas deveria acompanhar as mudanças nos regulamentos, mas ele estima que isso seja impossível.

\section{Empresa G}

Embora já trabalhasse com os softwares BIM, o representante da empresa $G$ alertou que ainda existem interfaces a serem resolvidas, pois esses softwares - para ser utilizados na totalidade das suas possibilidades - se tornariam muito complexos devido ao excesso de informações a ser gerenciadas. Os profissionais ainda precisam se acostumar com essa nova ferramenta de projeto.

A empresa possui um software de gerenciamento de documentos e dados de projeto, desenvolvido conforme as suas próprias necessidades.

\footnotetext{
${ }^{3}$ Projeto PEREN (PERformance ENergétique et environnement pérenne). Resumo disponível em: <http://www.batimentenergie.org/fileadmin/user_upload/peren/peren_resume_231008 .pdf>.
}

\section{Empresa $\mathrm{H}$}

$\mathrm{O}$ representante da empresa $\mathrm{H}$ lamentou o fato de a empresa ainda não trabalhar com os softwares BIM no desenvolvimento de projetos, mas apenas na simulação do desempenho técnico.

\section{Análise e discussão dos resultados}

Com o objetivo de facilitar a comparação entre as respostas obtidas, foram elaborados dois quadros que apresentam a síntese dos principais aspectos destacados nas entrevistas realizadas. No Quadro 5 são apresentados os pontos-chave das respostas dadas pelos profissionais dos escritórios de arquitetura, e no Quadro 6, das respostas apresentadas pelos consultores e incorporadores/construtores.

Com relação ao processo $\mathrm{HQE}^{\circledR}$, a análise das respostas apresentadas pelos entrevistados, e a sua correlação com o tipo de cliente atendido, permitiu identificar que o método era aceito pelos profissionais, mais enquanto ferramenta para auxiliar no desenvolvimento do projeto do que como certificação da qualidade ambiental. A obrigatoriedade da certificação, exigida nos projetos públicos, foi criticada por alguns entrevistados.

Parte dos profissionais considerou a metodologia inglesa BREEAM mais interessante do que o método $\mathrm{HQE}^{\circledR}$, por ser mais intuitiva - permitindo maior flexibilidade aos arquitetos -, além de ser reconhecida internacionalmente.

A questão dos custos mais elevados da construção sustentável também foi citada por alguns entrevistados. Nesse sentido, para as obras realizadas por empresas privadas, estaria a critério do empreendedor valorizar, ou não, a realização de projetos considerando os requisitos da construção sustentável. Nesse sentido, o representante da empresa $\mathrm{H}$ citou o crescente interesse dos investidores privados na certificação ambiental como forma de valorizar o patrimônio. Já as obras públicas exigem o atendimento aos requisitos do método $\mathrm{HQE}^{\circledR}$.

Com relação à gestão do processo do projeto, na opinião dos entrevistados, não seria possível realizar qualquer projeto que pensasse a questão ambiental sem preparar um sistema que permitisse a gestão das informações, necessárias à sua realização. Nesse particular, todos os entrevistados alegaram possuir algum sistema específico para o controle de documentos e dados, com destaque para as empresas $\mathrm{C}, \mathrm{G}$ e $\mathrm{H}$, que desenvolveram os seus próprios softwares para essa questão, facilitando a gestão e a troca de informações entre todos os atores envolvidos. 


\begin{tabular}{|c|c|c|c|}
\hline & $\begin{array}{l}\text { Com relação à construção sustentável } \\
\text { na França e à certificaçąa } H Q E^{\circledR}\end{array}$ & $\begin{array}{l}\text { Com relação à organização das empresas } \\
\text { para a produção da edificação sustentável }\end{array}$ & $\begin{array}{c}\text { Com relação à interoperabilidade na } \\
\text { produção de edificações sustentáveis } \\
\text { e à utilização de softwares BIM }\end{array}$ \\
\hline $\boldsymbol{A}$ & $\begin{array}{l}\text { Afirmou que as exigências do método } \\
\text { já eram cumpridas devido ao rigoroso } \\
\text { regulamento francês. } \\
\text { Considera o momento difícil para o } \\
\text { estabelecimento de uma cultura de } \\
\text { construção sustentável devido às } \\
\text { mudanças econômicas. }\end{array}$ & $\begin{array}{l}\text { Considera que a certificação } \mathrm{HQE}^{\circledR} \text { exige } \\
\text { certo formalismo, sendo necessária a } \\
\text { organização de um sistema de gestão das } \\
\text { informações para facilitar o atendimento aos } \\
\text { requisitos propostos. }\end{array}$ & Não trabalhava com softwares BIM. \\
\hline $\boldsymbol{B}$ & $\begin{array}{l}\text { Citou entraves da legislação francesa à } \\
\text { adoção de diretrizes da construção } \\
\text { sustentável, sendo necessária, } \\
\text { portanto, uma revisão. } \\
\text { É contrário à obrigatoriedade da } \\
\text { certificação } H Q E^{\mathbb{Q}} \text {, embora considere } \\
\text { o método positivo como orientação aos } \\
\text { arquitetos. }\end{array}$ & $\begin{array}{l}\text { Considera que, como grande parte dos } \\
\text { escritórios de arquitetura na França são de } \\
\text { pequeno porte ( } 1 \text { ou } 2 \text { arquitetos), o sistema } \\
\text { de gestão organizado conforme a norma ISO } \\
9001 \text { (INTERNATIONAL..., 2008) seria } \\
\text { inadequado devido à quantidade de } \\
\text { documentos e registros. }\end{array}$ & $\begin{array}{l}\text { Já trabalhava com um dos softwares } \\
\text { que utilizam a lógica BIM e } \\
\text { considerava a interoperabilidade um } \\
\text { aspecto a ser tratado com atenção. }\end{array}$ \\
\hline$C$ & $\begin{array}{l}\text { Acredita que a conscientização para a } \\
\text { construção sustentável ainda não } \\
\text { estaria totalmente difundida. } \\
\text { Considera que o atendimento à } \\
\text { certificação } \mathrm{HQE}^{\circledR} \text { não é suficiente } \\
\text { para garantir a produção de edificações } \\
\text { sustentáveis. }\end{array}$ & $\begin{array}{l}\text { Acredita que, para realizar o projeto } \\
\text { sustentável, a empresa de arquitetura precisa } \\
\text { se organizar devido à grande quantidade de } \\
\text { informações a serem consideradas no } \\
\text { processo de projeto. }\end{array}$ & Não trabalhava com softwares BIM. \\
\hline$D$ & $\begin{array}{l}\text { Considera que nem todos os arquitetos } \\
\text { franceses trabalham dentro dos } \\
\text { princípios do desenvolvimento } \\
\text { sustentável. } \\
\text { Não identifica grandes diferenças entre } \\
\text { as certificações HQE }{ }^{\circledR}, \text { BREEAM ou } \\
\text { LEED. }\end{array}$ & $\begin{array}{l}\text { Iniciou a organização do sistema de gestão } \\
\text { da qualidade da empresa, conforme os } \\
\text { requisitos da norma ISO 9001 } \\
\text { (INTERNATIONAL..., 2008), mas decidiu } \\
\text { não certificar a empresa, pois considera } \\
\text { exagerada a quantidade de documentos e } \\
\text { registros exigidos. } \\
\text { Acredita que um sistema de gestão } \\
\text { organizado pode ajudar o profissional na } \\
\text { realização dos projetos de edificações que } \\
\text { atendam aos requisitos de uma certificação } \\
\text { ambiental, tal como o } \mathrm{HQE}^{\circledR} \text {. }\end{array}$ & $\begin{array}{l}\text { Já trabalhava há muitos anos com } \\
\text { softwares que utilizam a lógica BIM, } \\
\text { mas enfrentava dificuldades com os } \\
\text { parceiros que não o utilizavam. } \\
\text { Citou vantagens, especialmente na } \\
\text { fase de concepção arquitetônica, pela } \\
\text { facilidade na compatibilização e } \\
\text { simulação de desempenho. }\end{array}$ \\
\hline
\end{tabular}

Quadro 5 - Síntese das respostas dos representantes dos escritórios de arquitetura

Especificamente no que se refere à certificação dos sistemas de gestão da qualidade conforme a norma ISO 9001 (INTERNATIONAL..., 2008), seis empresas acreditavam que o sistema de gestão precisaria estar formalizado, embora não necessariamente certificado. Nas empresas onde o sistema de gestão da qualidade existia e estava certificado (metade da amostra), os profissionais confessaram que não saberiam mais trabalhar sem a base documental exigida por aquele sistema. Ressalta-se que todos os entrevistados reconheceram o potencial de um sistema de organização das informações para a realização de projetos com alta qualidade ambiental, uma vez que ele facilitaria o desenvolvimento do projeto integrado.

Os entrevistados também reconheceram a importância da interoperabilidade no processo de projeto, especialmente para a realização do projeto da edificação sustentável. Entretanto, de acordo com o representante da empresa $\mathrm{F}$, o trabalho colaborativo funcionaria para as soluções já existentes, mas não possibilitaria a geração de soluções inovadoras. Ele acredita que, para gerar soluções inovadoras, a troca de informações pelo método tradicional seria mais eficiente - com os profissionais discutindo pessoalmente as possíveis soluções de projeto.

O uso de softwares que utilizam o BIM foi citado apenas por alguns entrevistados. A empresa $\mathrm{D}$, que o utiliza há bastante tempo no desenvolvimento dos seus projetos (10 anos), encontrava dificuldades na relação com os profissionais de outras empresas, uma vez que estes nem sempre utilizavam um software dessa natureza.

Duas empresas demonstraram certa preocupação em relação à interoperabilidade propiciada pelos softwares BIM, uma vez que, segundo apontaram, se todos os profissionais puderem trabalhar no projeto simultaneamente, nunca se saberá qual é a última revisão daquele projeto. Esse aspecto chamou a atenção para outra questão: a utilização de softwares que permitem o desenvolvimento integrado do projeto demanda um sistema de gestão do trabalho que permita que essa interoperabilidade possa, de fato, contribuir para o processo de projeto, e não torná-lo ainda mais confuso. 


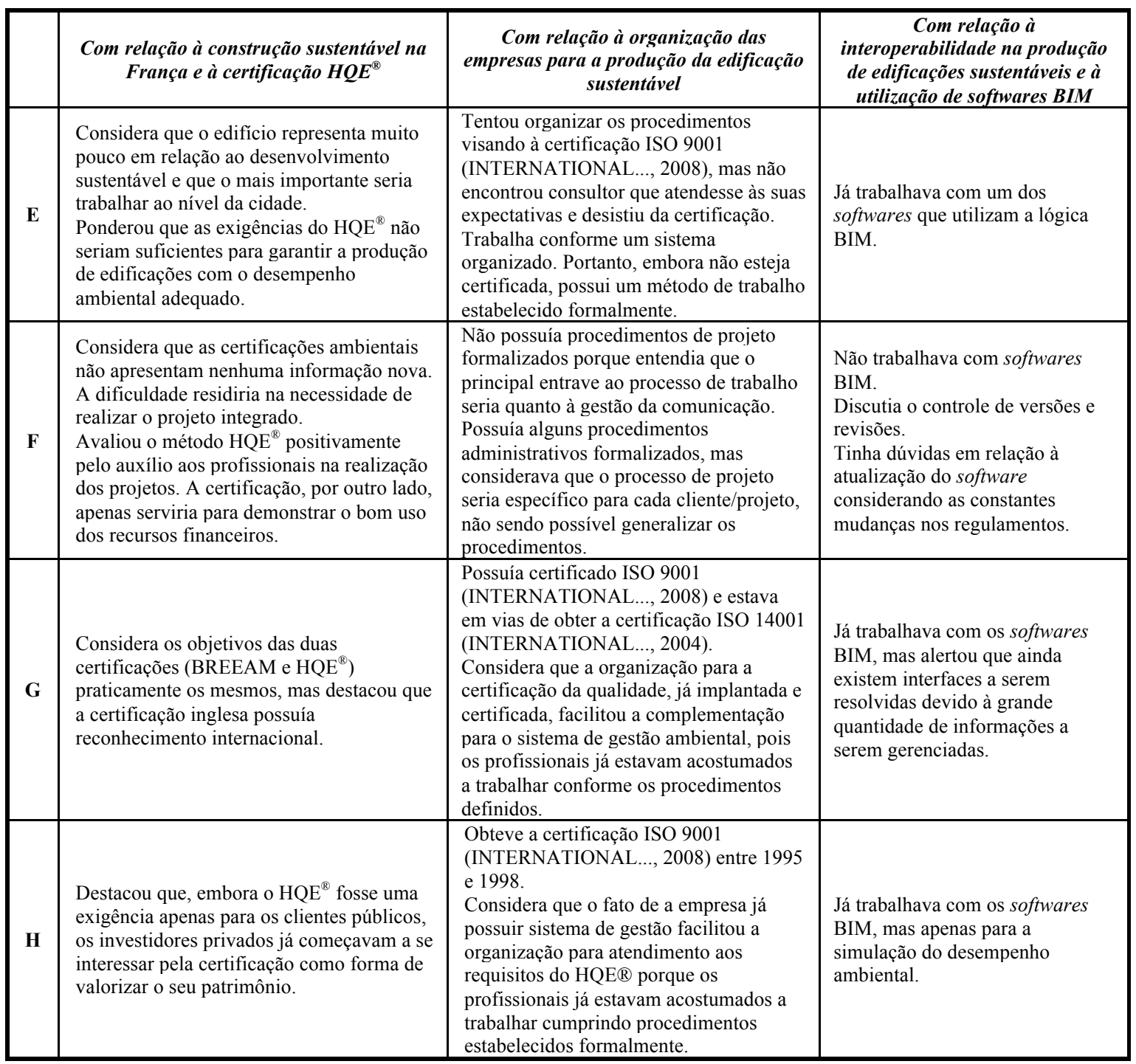

Quadro 6 - Síntese das respostas dos representantes das empresas de consultoria (E e F) e construtores/incorporadores ( $\mathrm{G} \mathrm{e} \mathrm{H}$ )

\section{Conclusões}

O desenvolvimento de qualquer projeto implica a definição de um sistema de gestão eficiente, para que as informações das diferentes especialidades não se percam. No que se refere à produção de edificações sustentáveis, o processo de troca de informações, entre as diferentes especialidades, deve ter início, obrigatoriamente, na fase da concepção arquitetônica. Ou seja, não será mais possível ao arquiteto que tenha a preocupação com as questões ambientais a concepção da edificação individualmente, sem a participação dos especialistas das diferentes especialidades (estrutura, iluminação, térmica, acústica, etc.). Essa constatação, se, em um primeiro momento, pode causar certa preocupação, especialmente no que se refere à questão da autoria do projeto arquitetônico, não deve ser entendida como uma "ameaça" ao ato criativo dos arquitetos. O que se percebeu, com a pesquisa realizada na França, foi o estabelecimento de parcerias entre os diferentes profissionais, sem que isso implicasse o desrespeito às decisões conceituais do arquiteto, responsável pela concepção do projeto. A consulta aos especialistas passou a fazer parte do processo de projeto. Naturalmente, o projeto proposto originalmente pode sofrer ajustes, em função das informações dos especialistas, mas esses ajustes são decididos por todos os profissionais, atuando de forma colaborativa. Ou seja, para a realização de projetos para a produção de edificações sustentáveis a gestão das informações terá um papel ainda mais importante.

Com relação à certificação do sistema de gestão da qualidade, observou-se que, embora estivesse sendo perseguida por algumas empresas, não seria, 
em si, a meta. Por outro lado, a organização documental e das informações (que pode, ou não, vir acompanhada por uma certificação) foi encarada como aspecto fundamental. Ressalta-se que as empresas entrevistadas informaram que não saberiam mais como trabalhar sem um adequado sistema de gestão, uma vez que a troca de informações entre os profissionais precisa estar organizada. Dessa forma, pode-se compreender que, sem a implantação de um sistema de gestão das informações, um escritório de projeto terá dificuldade em lidar com a grande quantidade de requisitos necessária ao processo de projeto da edificação com alta qualidade ambiental, bem como com a gestão da comunicação entre os diferentes parceiros, necessariamente envolvidos no processo.

Com relação às novas tecnologias que permitem a modelagem digital da edificação, viabilizando a compatibilização das decisões projetuais (BIM), cabe destacar que será necessário o estabelecimento, pelas empresas interessadas em utilizar essa tecnologia, de um sistema de gestão que defina as regras para o seu uso. Um dos entrevistados afirmou que a principal preocupação seria quanto ao ponto final dos projetos. Se todos os profissionais puderem intervir simultaneamente no projeto, ficará o temor de que nunca ninguém saberá ao certo qual a sua última versão (ou, em qual versão se deverá trabalhar). Ou seja, há que se entender a lógica das ferramentas de tecnologia da informação, integrar essa lógica dentro do processo de projeto da edificação e, posteriormente, identificar os impactos dessa prática nos processos de gestão das empresas.

Embora esse aspecto tenha sido mencionado por apenas um entrevistado, o entendimento de que as metas do desenvolvimento sustentável na construção civil não deveriam se limitar aos métodos de auxílio à realização de projetos de alta qualidade ambiental, nem à produção tão-somente de edificações (HQE ${ }^{\circledR}$, BREEAM, LEED), merece destaque. Dentro dessa visão, a preocupação com a edificação sustentável seria apenas o começo de um processo muito mais complexo, que deve estender-se ao projeto das cidades, envolvendo a formulação de políticas para o desenvolvimento urbano sustentável.

O processo da construção sustentável na França não teve início com o método $\mathrm{HQE}^{\circledR}$. O governo francês tem publicado, há mais de dez anos, regulamentos térmicos que exigem dos construtores a produção de edificações com baixo consumo energético. Ou seja, naquele país o $\mathrm{HQE}^{\circledR}$ veio como consequência (desdobramento natural) de uma preocupação anterior com a sustentabilidade ambiental, particularmente com a eficiência energética nas edificações.

No Brasil nunca houve qualquer regulamento que exigisse a redução no consumo energético ou a concepção de edificações mais eficientes. Mesmo hoje, quando já existem algumas propostas (Selo Azul, Procel, Aqua), nenhuma tem caráter compulsório, tal como o $\mathrm{HQE}^{\circledR}$ na França, para as edificações públicas. Talvez por esse motivo a implantação da cultura da construção sustentável no Brasil ainda esteja lenta, pois ela não se constitui no resultado de um processo cultural de conscientização gradativa, mas numa questão alavancada por iniciativas externas.

Finalmente cabe mencionar que as metodologias estrangeiras de apoio ao projeto com qualidade ambiental pouca (ou quase nenhuma) referência fazem aos aspectos relacionados com os desafios sociais e econômicos, porque, provavelmente, à época da elaboração de tais métodos essas questões estariam satisfatoriamente equacionadas nos seus países de origem. O Selo Azul, da Caixa, se destaca em relação aos modelos europeus e norte-americanos justamente por premiar as iniciativas que envolvem a educação ambiental, entre outras práticas sociais. Entende-se que, além de projetar edificações com qualidade ambiental, será necessário conscientizar as populações em relação ao seu papel dentro do processo do desenvolvimento sustentável.

\section{Referências}

ASSOCIATION HQE. Haute Qualité

Environnementale. Statuts de l'Association, Disponível em:

$<$ http://assohqe.org/hqe/IMG/pdf/STATUTS.pdf $>$. Acesso em: 5 dez. 2011.

\section{BREEAM OFFICES. Scheme Document SD}

5055. BRE Global Ltd., 2010.

BRUNDTLAND, G. H. Report of the World Commission on Environment and Development: our common future Oslo. Report, 20 mar. 1987.

Disponível em:

$<$ http://upload.wikimedia.org/wikisource/en/d/d7/

Our-common-future.pdf $>$. Acesso em: 4 jan. 2012.

\section{CASTELLS, A. L'Architecture et la Haute}

Qualité Environnementale. Centre

Interprofessionnel de Formation Continue de l'Architecture, Module Du 18 juin 2010, Ecole d'Architecture de Toulouse, Toulouse, 2010. 
CHAPMAN, R. E. Inadequate Interoperability: a closer look at the costs. In: INTERNATIONAL SYMPOSIUM ON AUTOMATION AND ROBOTICS IN CONSTRUCTION ISARC, 22., Ferrara, 2005, Procedings... Ferrara, 2005.

CONSEIL NATIONAL DE L'ORDRE DES ARCHITECTES. Le Guide du Jure HMONP. Conseil National De L'Ordre des Architectes, 2010.

ELETROBRAS; PROCEL EDIFICA.

Etiquetagem de Eficiência Energética de Edificações. 2010. Disponível em:

$<$ http://www.procelinfo.com.br/data/Pages/LUMIS A84BD56DPTBRIEGUEST.htm>. Acesso em: 17 jan. 2012.

FERRIES, B. Étude des Coûts des Défauts d'Interopérabilité Supportés par Entreprises, Maîtres d'Ouvrage et Exploitants, Dans le Cadre de la Construction et l'Exploitation de Bâtiments. Club des Prescripteurs du BIM, 29 mars 2010. Disponível em:

$<$ http://lra.toulouse.archi.fr/club-des-usages/>. Acesso em: 14 ago. 2010.

FERRIES, B. L'Essentiel Maquette Numerique du Batiment BIM - IFC. 2009. Disponível em $<$ http://www.laurenti.com/publis/bimsbook.pdf $>$. Acesso em: 12 jan. 2012.

FUNDAÇÃO VANZOLINI. [Site institucional]. Disponível em:

$<$ http://www.vanzolini.org.br/noticias.asp?cod_site $=0 \& i d \_$noticia $=132>$. Acesso em: 30 ago. $201 \overline{2}$.

GREEN BUILDING COUNCIL BRASIL. [Site institucional]. Disponível em:

$<$ http://www.gbcbrasil.org.br/?p=certificacao $>$. Acesso em: 30 ago. 2012.

GREEN GLOBES. The Practical Building

Rating System. Disponível em:

$<$ http://www.greenglobes.com $>$. Acesso em: 30 ago. 2011.

INTERNATIONAL COUNCIL FOR RESEARCH AND INNOVATION IN BUILDING AND CONSTRUCTION. Agenda 21 for Sustainable Construction in Developing Countries: a discussion document. CSIR Building and Construction Technology, Pretoria, 2002.

INTERNATIONAL ORGANIZATION FOR STANDARDIZATION. ISO 9001: quality management standard. London, 2008.

INTERNATIONAL ORGANIZATION FOR STANDARDIZATION. ISO 14001:

environmental management. London, 2004.
JOHN, V. M.; RACINE, T. A. P. (Coords.). Boas Práticas Para Habitação Mais Sustentável: Selo Caixa Azul. São Paulo: Páginas \& Letras, 2010.

PLATZER, M. Mesurer la Qualité

Environnementale des Bâtiments. Paris: Le Moniteur, 2009.

POUCHARD, L. C.; CUTTING-DECELLE, A. Ontologies and Standard-Based Approaches to Interoperability for Concurrent Engineering. In: ANUNBA, C. J.; KAMARA, J. M.; CUTTINGDECELLE, A. (Orgs.). Concurrent Engineering in Construction Projects. Nova Iorque: Taylor and Francis, 2007. p. 118-160.

REED, R. et al. International Comparison of Sustainable Rating Tools. Journal of Sustainable Real State, v. 1. n. 1, 2009. Disponível em: $<$ http://www.costar.com/josre/JournalPdfs/01Sustainable-Rating-Tools.pdf $>$. Acesso em: 7 jul. 2011.

REFERENTIAL Qualiprom $^{\circledR}$; Management des Processus de Réalisation Opérationnels Promoteur-Constructeur. Paris, 2002. Disponível em:

$<$ http://fcardoso.pcc.usp.br/QUALIPROM_referen tiel.pdf>. Acesso em: 06 dez. 2012.

SALGADO, M. S. Implementation of Quality Management System on Architecture Offices as a Requirement for Sustainable Design In: ARCHITECTURAL MANAGEMENT INTERNATIONAL CONFERENCE, Vienna, 2011. Proceedings... Vienna, 2011.

SALGADO, M. S.; LEMOS, H. Guidelines for the Certification of Laboratory Architectonic Design, Considering Quality, Environment and Safety Requirements. In: WORLD SUSTAINABLE BUILDING CONFERENCE, Tokyo, 2005. Proceedings... Tokyo, 2005.

SILVA, V. G. Indicadores de Sustentabilidade de Edifícios: estado da arte e desafios para desenvolvimento no Brasil. Ambiente Construído, Porto Alegre, v. 7, n. 1, p. 47-66, jan./mar. 2007.

\section{Agradecimentos}

Os autores agradecem aos diretores e representantes das empresas francesas que concordaram em participar desta pesquisa: Cardete et Huet Architectes, Groupe GA, Enzo \& Rosso, Tisseyre et Associés, Vigneu et Zilio Sarl Architecture, Séquences Architectes Toulouse, Groupe IOSIS Paris, e Gamba Acoustique. Também aos professores Bernard Ferries e Gerard Ringon, à Capes, pelo financiamento da pesquisa

98 Salgado, M. S.; Chatelet, A.; Fernandez, P. 
(bolsa de pós-doutorado), e ao CNPq (bolsa de produtividade em pesquisa).

Revista Ambiente Construído

Associação Nacional de Tecnologia do Ambiente Construído

Av. Osvaldo Aranha, $99-3^{\circ}$ andar, Centro

Porto Alegre - RS - Brasil

CEP 90035-190

Telefone: +55 (51) 3308-4084

Fax: +55 (51) 3308-4054

www.seer.ufrgs.br/ambienteconstruido

E-mail: ambienteconstruido@ufrgs.br 